\title{
Perceptions of care after end-of-treatment among younger women with different gynecologic cancer diagnoses - a qualitative analysis of written responses submitted via a survey
}

\author{
Elisabet Mattsson'1, Lisa Ljungman², Kim Einhorn², Inger Sundström Poromaa², Karin Stålberg²
} and Anna Wikman ${ }^{2 *}$ (1)

\begin{abstract}
Background: Less attention has been given to younger adults' psycho-oncology care needs than to children and older adults with cancer. The aim was to explore how care following end-of-treatment was perceived by women treated for different gynecologic cancer diagnoses during younger adulthood.

Methods: A sample of 207 women diagnosed with gynecologic cancer 2008 to 2016, aged 19-39 at time of diagnosis answered one open-ended question regarding important aspects of care after end-of-treatment. The written responses were analyzed with manifest content analysis and presented in relation to the women's diagnoses, i.e., cervical ( $n=130)$, ovarian $(n=57)$, and other gynecologic cancer diagnoses $(n=20)$.

Results: The analysis resulted in three categories: Unmet long-term supportive care needs, Satisfying long-term supportive care, and Health care organizational difficulties. Over half of the women (66.7\%) described unmet care needs. The corresponding figures were 80.7, 63.1 and 50\% for women diagnosed with ovarian, cervical and other gynecologic cancer diagnoses, respectively. Satisfying supportive care were described by approximately one quarter of the women (26.1\%). Among women diagnosed with ovarian cancer $14 \%$ described satisfying supportive care. The corresponding figures were 26.9 and $30 \%$ for women diagnosed with cervical cancer and other gynecological diagnoses, respectively. Approximately one quarter of the women, irrespectively of diagnosis, described aspects related to health care organizational difficulties (28\%).
\end{abstract}

Conclusions: The results highlight the importance of good quality care linked to the diagnosis and based on an understanding of the woman's need, desire and expectation of support after end-of-treatment.

Keywords: Young adult, Cancer, Gynecologic, Oncology, Survivorship, Quality of life

*Correspondence: anna.wikman@kbh.uu.se

${ }^{2}$ Department of Women's and Children's Health, Uppsala University,

Uppsala, Sweden

Full list of author information is available at the end of the article

\section{Background}

Young adults with cancer face specific challenges and needs that differ from those of children and older adults with cancer $[1,2]$ including delays in diagnosis $[1,3]$, difficulties with adherence to treatment $[2,3]$, financial concerns [1], and more pronounced psychological 
supportive care needs $[1,4]$. Sexual problems pose great concerns, particularly among women [5], and the importance of counselling young adult cancer patients around fertility and sexuality issues has been stressed $[5,6]$. Also, the 5-year survival rate of persons diagnosed with cancer between the ages of 15 and 29 has seen little improvement over the past decades, compared to younger or older cancer patients [7].

Gynecologic cancers, i.e., cervical, ovarian, uterine, vaginal and vulvar cancer, are the second most common cancers among women [8-11] and account for approximately $8 \%$ of all cancer diagnoses among women aged 20-39 years [8]. Women diagnosed with cervical cancer are often premenopausal [12], i.e., diagnosed before 50 years of age. Consequences of radiation treatment are common distressing symptoms, and infertility related to cancer treatment represents an important care need in this group [12]. Ovarian cancer is considered a lowprevalence but high-consequence disease [9]. It has the poorest prognosis of all gynecologic malignancies [9]. Following end-of-treatment, women diagnosed with ovarian cancer face regular surveillance including a high likelihood of recurrence [10]. Contrary to ovarian cancer, the prognosis for premenopausal women with early stage endometrial cancer is favorable, with a 5 -year survival rate greater than $90 \%$ [11]. However, the standard surgical treatment, i.e., total abdominal hysterectomy, bilateral oophorectomy, and pelvic/para-aortic lymphadenectomy, significantly reduce the post-operative quality of life for young women due to symptoms of menopause, fertility loss, lymphedema and increased risk of cardiovascular disease [13]. Lastly, vulvar cancer can affect younger women with high-risk human papillomavirus infection [8]. Long-term impact of vulvar surgery often implies dyspareunia, fatigue, pain, and sexual problems [14]. Taken together, despite different disease trajectories for each gynecologic cancer diagnosis, the treatments may cause side-effects such as cardiovascular disease, fatigue, infertility, pain, sexual dysfunction, urinary complications, and premature menopause among younger women [13-15].

Women diagnosed with gynecologic cancer face not only physical symptoms of disease and treatment, but a multitude of psychological and social consequences. The emotional impact of gynecologic cancer is significant and clinical levels of anxiety, depression, and posttraumatic stress disorders (PTSD) as well as cancer-specific distress have been reported among survivors [16-19]. In addition, survivors report a gap between supportive care services and the need of such services [18, 19]. Supportive care needs in the context of cancer has been defined as "the provision of the necessary services for those living with or affected by cancer to meet their informational, emotional, spiritual, social, or physical needs during the diagnostic, treatment or follow up phases encompassing issues of health promotion and prevention, survivorship, palliation, and bereavement" [20]. The extent of unmet supportive care needs is, in turn, often associated with symptoms of anxiety, depression, PTSD and poorer quality of life [19]. In most previous studies, women diagnosed during young, middle, and late adulthood are lumped together and, consequently, no conclusions can be drawn as to whether these results can be generalized to women diagnosed at a younger age despite findings showing that younger age is a risk factor for greater unmet needs [21]. In fact, few studies in general have specifically focused on mental- and physical health of women diagnosed with cancer during young adulthood [22] with less attention given to young adults' psychooncology care needs than to children and older adults with cancer [3]. Against this background, the aim of the present study was to explore how care following end-oftreatment was perceived by women treated for different gynecologic cancer diagnosis during younger adulthood.

\section{Methods}

\section{Study design}

This study was part of a cross-sectional survey using mixed-methods to explore important aspects of care following end-of-treatment perceived by women diagnosed with gynecologic cancer during young adulthood. The present study includes data from the qualitative part of the survey. Eligibility criteria were: a diagnosis of gynecologic cancer between 2008 and 2016 included in the Swedish Quality Registry for Gynecologic Cancer, aged 19-39 at time of diagnosis, and having completed primary treatment. Exclusion criteria were: borderline tumors of the ovary, or carcinoma in situ of the cervix, vulva, or vagina.

\section{Study sample}

Ethical approval to conduct the study was granted by the Regional Ethical Review Board in Uppsala, Sweden (Reference number: 2016/221). Potential participants were identified via the Swedish Quality Register for Gynecologic Cancer [23]. The register consists of four sub-registries: i) ovarian cancer (ICD-10: C56.9, C57.0, C48.1, C48.2, C76.2, C76.3), including fallopian tube, peritoneal, and abdominal or pelvic cancers, available since 2008; ii) uterine cancer (ICD-10: C54), available since 2010; iii) cervical and vaginal cancer (ICD-10: C52, C53), since 2011; iv) vulvar cancer (ICD-10: C51), available since 2012. The data input in the register is validated against the Swedish Cancer register and medical records [23]. Information on contact details were obtained via 
data linkages to the SPAR-register (the Swedish personal address register).

\section{Data collection}

Potential participants were sent information about the study together with a study-specific questionnaire to complete and return by post. The information letter contained a study code, which enabled participants to complete the survey online should they prefer. By responding to the survey, participants provided informed consent to participate in the study. Up to two reminder letters were sent. In brief, the questionnaire included questions addressing cancer-related distress, needs for psycho-social support, previous psychological/psychiatric distress, and received psychological support. In addition, socio-demographic information was collected and included marital status, number of children, and education. Answers were given via fixed options and/or written open responses. For a detailed presentation of results of the study-specific questionnaire, see Mattsson et al. (2018) [4]. The present study includes data from the qualitative part of the survey, not previously reported. For this part, one open-ended question was included where women were asked to freely describe anything they felt was important to share in relation to their needs and experiences after end of treatment ("Please describe anything you feel is important to share in relation to your needs and experiences after end of treatment").

Clinical data were obtained from the Swedish Quality Register for Gynecologic Cancer [23] and included date of birth, diagnosis, date of diagnosis, treatment, and date of treatment completion. As information on recurrence is not yet reliable in the register, such data were not obtained.

\section{Data analysis}

The written responses were analyzed with content analysis, a method that can be used to draw valid conclusions about a manifest message by systematic identification of specified written characteristics [24]. The responses were read repeatedly by the first and last author to gain an overall understanding. Words and sentences, i.e., recording units, containing relevant information regarding important aspects of care following end-of-treatment were identified. The first and last author grouped recording units into exclusive categories reflecting central messages. Recording units in the same category are assumed to have a similar meaning, based on either the precise meaning of the words or of words sharing the same connotations. The authors defined the boundaries of each category and developed final descriptions of the central characteristics of each category. The analytic process was flexible and iterative, i.e., steps were repeated when needed and the analysis was reviewed in relation to the raw data during all steps. When categories were identified, the first and last author scrutinized the results and were involved in discussion until all authors felt the results adequately reflected the content in the written responses. Counting was integral to the analysis process to recognize potential patterns in data and deviations from those patterns, as well as to make analytic generalizations from data [25]. Consequently, recording units in the same category were counted (numbers (n) and percentages (\%)) and presented in relation to the women's diagnoses, i.e., cervical, ovarian, and other gynecologic cancer. Even if a respondent mentioned a certain recording unit several times, it was only counted once in the results. The COREQ (consolidated criteria for reporting qualitative research) checklist was used to guide the analysis and the reporting [26]. However, participants did not provide feedback on the findings as no relationship was established between the researchers and participants due to the study's design, i.e., survey. Data were analyzed using NVivo Pro for Windows version 11.3 (QRS International Pty. Ltd., Australia).

Sample characteristics are described by frequencies and percentages, $\mathrm{n}$ (\%), for categorical variables and by means and standard deviations (SD), supplemented by median and range, for continuous variables. The statistical analyses were performed using SPSS Statistics for Windows, version 24 (IBM Corp., Armonk, N.Y., USA).

\section{Results}

Of 646 eligible, 337 (52\%) women responded to the survey. Of these, 207 (61.4\%) women responded to the specific open-ended question about what they felt important to tell us about regarding care following end-of-treatment. Characteristics of the study sample are shown in Table 1.

The median (range) age at diagnosis for the total sample $(n=207)$ was 35 (21-41) years. The corresponding figures for women diagnosed with cervical cancer $(n=130)$ were $35(25-41)$ years, and $34(21-41)$ and $38(23-41)$ years for women diagnosed with ovarian cancer $(n=57)$ and other diagnoses $(n=20)$, i.e., endometrial, pelvic and vulvar cancer, respectively. Most of the respondents $(67.6 \%)$ had a university degree. The median (range) age at time of study for the total sample $(n=207)$ was 37 (25-46) years. For most women $(n=111,53.6 \%)$ time since diagnosis ranged between 2 and 4 years. All participants had completed treatment at the time of the survey. Nearly half received multimodal treatment $(n=97$, $46.9 \%)$. Notably, the proportion of multimodal treatment among women with ovarian cancer $(n=46,79.7 \%)$ was more than double that of the proportion of multimodal treatment among women with cervical $(n=44,33.8 \%)$ or 
Table 1 Clinical and socio-demographic characteristics of 207 women after end-of-treatment for gynecologic cancer

\begin{tabular}{|c|c|c|c|c|}
\hline Characteristic & $\begin{array}{l}\text { Total } \\
(n=207)\end{array}$ & $\begin{array}{l}\text { Cervical cancer }(n=130, \\
62.8 \%)\end{array}$ & $\begin{array}{l}\text { Ovarian cancer } \\
(n=57,27.5 \%)\end{array}$ & $\begin{array}{l}\text { Other }^{\mathrm{a}} \\
(n=20,9.7 \%)\end{array}$ \\
\hline & Mean (SD) & Mean (SD) & Mean (SD) & Mean (SD) \\
\hline Age at diagnosis & $34.2(4.9)$ & $34.6(4.1)$ & $32.7(6.2)$ & $36.1(4.7)$ \\
\hline \multirow[t]{2}{*}{ Age at time of study } & $37.1(5.1)$ & $37.2(4.6)$ & $36.4(6.1)$ & $39.1(5.2)$ \\
\hline & n (\%) & n (\%) & n (\%) & n (\%) \\
\hline \multicolumn{5}{|l|}{ Treatment } \\
\hline Surgery & $110(53.1)$ & $86(66.2)$ & $11(20.3)$ & $13(65.0)$ \\
\hline $\begin{array}{l}\text { Surgery and/or chemotherapy } \\
\text { and/or radiotherapy }\end{array}$ & $97(46.9)$ & $44(33.8)$ & $46(79.7)$ & $7(35.0)$ \\
\hline \multicolumn{5}{|l|}{ Time since diagnosis } \\
\hline$\leq 1$ year & $52(25.1)$ & $38(29.2)$ & $11(19.3)$ & $3(15.0)$ \\
\hline 2-4years & $111(53.6)$ & $71(54.6)$ & $27(47.4)$ & $13(65.0)$ \\
\hline$\geq 5$ years & $44(21.3)$ & $21(16.2)$ & $19(33.3)$ & $4(20.0)$ \\
\hline \multicolumn{5}{|l|}{ Time since end-of-treatment } \\
\hline$\leq 1$ year & $68(32.8)$ & $46(35.4)$ & $17(29.8)$ & $5(25.0)$ \\
\hline 2-4years & $103(49.8)$ & $69(53.1)$ & $23(40.4)$ & $11(55.0)$ \\
\hline$\geq 5$ years & $36(17.4)$ & $15(11.5)$ & $17(29.8)$ & $4(20.0)$ \\
\hline \multicolumn{5}{|l|}{ Cohabitation at time of study } \\
\hline Cohabiting & $146(70.5)$ & $96(73.8)$ & $38(66.7)$ & $12(60.0)$ \\
\hline Non-cohabiting & $61(29.5)$ & $34(26.2)$ & $19(33.3)$ & $8(40.0)$ \\
\hline \multicolumn{5}{|l|}{ Education } \\
\hline University degree & $140(67.6)$ & $87(66.9)$ & $41(71.9)$ & $12(60.0)$ \\
\hline $\begin{array}{l}\text { Nine-years compulsory/upper } \\
\text { secondary }\end{array}$ & $64(30.9)$ & $41(31.5)$ & $16(28.1)$ & $7(35.0)$ \\
\hline Missing & $3(1.5)$ & $2(1.6)$ & $0(0)$ & $1(5)$ \\
\hline \multicolumn{5}{|l|}{ Children } \\
\hline Yes & $122(58.9)$ & $91(70.0)$ & $23(40.4)$ & $8(40.0)$ \\
\hline No & $84(40.6)$ & $38(29.2)$ & $34(59.6)$ & $12(60.0)$ \\
\hline Missing & $1(0.5)$ & $1(0.8)$ & $0(0)$ & $(0)$ \\
\hline
\end{tabular}

a Other $=$ Endometrial $(n=16)$, pelvic $(n=1)$, and vulvar cancer $(n=3) ; n$ numbers, SD Standard deviation

other gynecologic cancers $(n=7,35.0 \%)$. Similarly, the proportion of women with ovarian cancer $(n=23,40.4 \%)$ who reported having children was lower than among women with cervical cancer $(n=91,70.0 \%)$ but like other gynecologic cancers $(n=8,40.0 \%)$.

The content analysis resulted in three categories described below: Unmet long-term supportive care needs, Satisfying long-term supportive care, and Health care organizational difficulties. See Table 2 for a presentation of citations and numbers of recording units $(n, \%)$ in each category related to the different gynecological cancer diagnoses.

\section{Unmet long-term supportive care needs}

Over half of the women who responded to the question described aspects belonging to the category Unmet long-term supportive care needs (66.7\%). A majority of women diagnosed with ovarian cancer described unmet needs (80.7\%). The corresponding figures were 63.1 and $50 \%$ for women diagnosed with cervical cancer and other gynecologic cancer diagnoses, respectively. The content of the category includes descriptions of unmet psychological care needs after end-of-treatment, sometimes perceived as neglected by health care professionals. Some women considered information regarding late effects from surgery and treatments inadequate. In addition, women described distress regarding sexuality and infertility issues that was not acknowledged by the health care team. Concerns regarding how to deal with sexual problems and how these problems affect a relationship were raised. Some women also described a need for follow-up care where partners were offered to participate actively. 


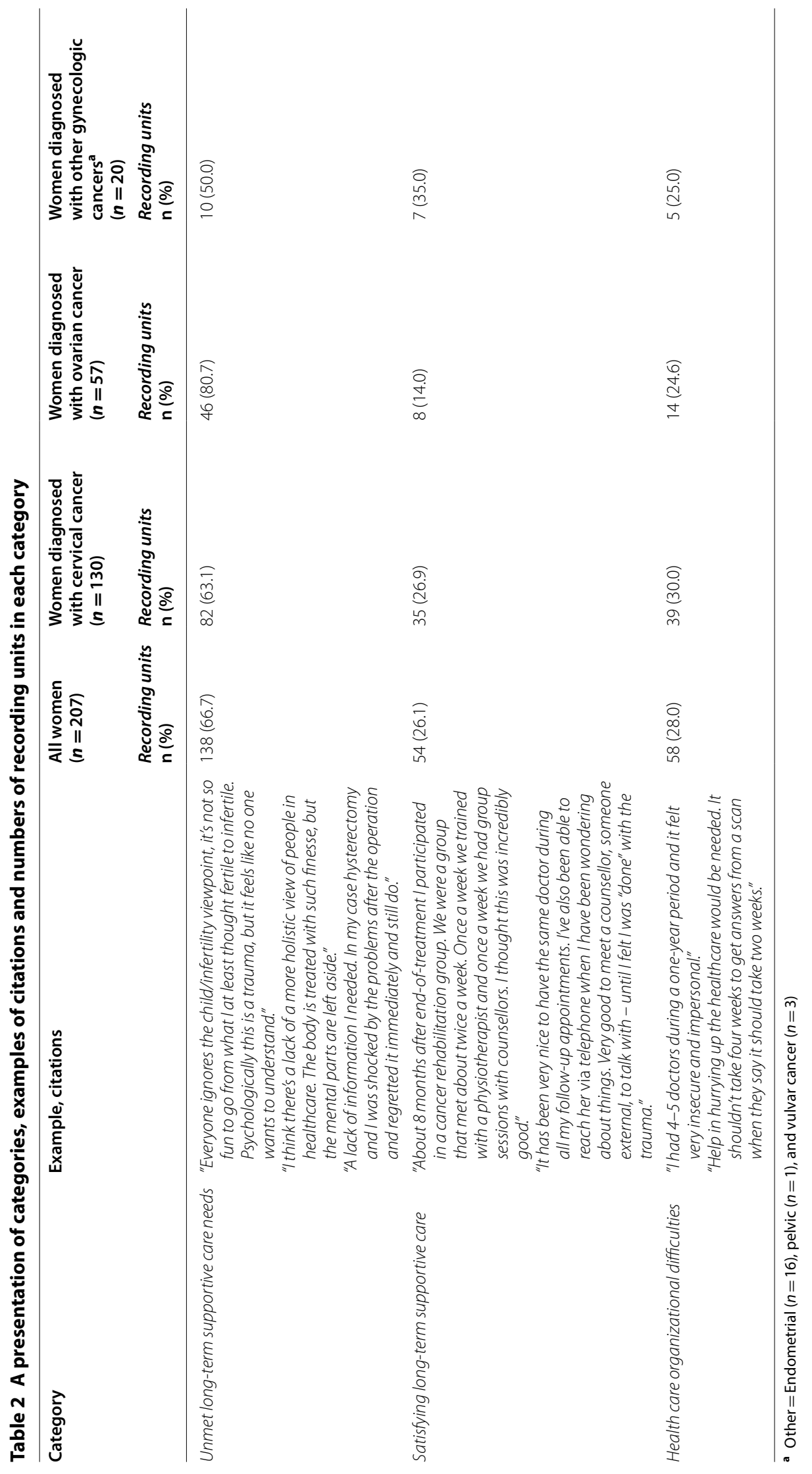




\section{Satisfying long-term supportive care}

About one in four women described aspects belonging to the category Satisfying long-term supportive care (26.1\%). However, among women diagnosed with ovarian cancer $14 \%$ described satisfying supportive care. The corresponding figures were 26.9 and $30 \%$ for women diagnosed with cervical cancer and other gynecologic cancer diagnoses, respectively.

The content of the category includes descriptions of satisfaction with the given care. These women stressed the importance of long-term continuity of health care professionals and the routinely offered psychosocial support following end-of-treatment. Other factors described as important were easy access to health care professionals and the availability of organized group support. Key concepts of good care were described by the women as meeting an interdisciplinary health care team involved in long-term health care management and psychosocial support. Meeting other women diagnosed with cancer together with different representatives from the health care was also considered important.

\section{Health care organizational difficulties}

Approximately one quarter of the women, irrespectively of diagnosis, described aspects belonging to the category Health care organizational difficulties.

The content of the category includes descriptions of experiences of non-continuity in the health care and worries related to extensive waiting times for test results. These aspects were in turned described to create worries. In addition, administration differences between health care regions regarding sick leave were described.

\section{Discussion}

The aim of this study was to describe important aspects of gynecologic cancer care following end-of-treatment as perceived by younger adult women, and to explore these aspects in relation to the different gynecologic cancer diagnoses. The results revealed three categories representing the answers from the participants: Unmet long-term supportive care needs, Satisfying long-term supportive care, and Health care organizational difficulties.

The most prominent reported aspect of care belonged to the category Unmet long-term supportive care needs (66.7\%). The proportion of women reporting answers in this category varied between the different gynecologic cancer diagnoses with the highest frequency observed among women with ovarian cancer (80.7\%). Results from a large survey of supportive care needs including 303 women with gynecologic cancer found no association between reported needs and type of cancer [27]. However, one recent review of supportive care needs in cancer found associations with sociodemographic (e.g., younger age, lower socioeconomic status, having no children) and clinical factors (e.g., more advanced disease, multiple cancer sites) that influenced the magnitude of unmet needs [28]. Overall, women experienced that their psychological care needs were neglected by health care professional, and when treatment was completed, they were left alone with their feelings related to the cancer experience. Some also reported the period after end-oftreatment as particularly challenging. These findings correspond with previous studies of supportive care needs, where women described needs for distress screening and support $[29,30]$ and a desire to be offered appropriate supportive care services and follow-up after treatment [29-33]. A key barrier to psychosocial care perceived by patients is the perception by health care providers that psychosocial care is not needed [34].

Women also described a lack of information regarding late effects from the treatment they had received. Common important needs for information in general [35], or information about coping with e.g., fear of recurrence [35], side effects [35, 36] and daily living [36] have been reported previously. Not surprisingly, women described significant distress regarding sexuality and fertility. It is well known that women with gynecologic cancer may face additional, specific problems, compared with other cancer diagnoses, including loss of fertility, sexual dysfunction, bowel dysfunction, fecal and urinary incontinence and emotional and psychological issues related to body image, sexuality and relationships $[9,12,13,15]$. In a longitudinal study of women with ovarian cancer, unmet needs in the domains of information, patient care and sexuality were reported to decrease over a two-year period following diagnosis, whereas needs relating to psychological and physical domains remained moderateto-high during the same time period [37]. In contrast, in the present study unmet information needs, distress regarding sexuality and fertility were reported in the longer term, most women were at least two years postdiagnosis and comprised a much younger age group in general. This is line with previous studies that have shown younger women with gynecologic cancer to be at greater risk of distress and experiencing unmet needs [21].

One in four women reported answers belonging to the category Satisfying long-term supportive care. Answers in this category concerned continuity in terms of health care professionals during the whole disease trajectory, having been offered psychosocial support services routinely, and meeting other women in the same situation. These answers reflect previous findings regarding important factors with regard to support in relation to a cancer experience. A qualitative study exploring psychosocial distress, coping and social support among women with ovarian cancer reported that when the participants 
were asked who they thought would be most beneficial to talk to about their experiences of cancer, most women responded that another survivor would be the best [38]. Peer support and participation in other forms of support groups are associated with positive results and experiences among patients with gynecologic cancer [39]. It is important to note though, that the proportion of women who experienced satisfying long-term supportive care varied between the different gynecologic cancer diagnoses included in this study with the lowest figure observed among women with ovarian cancer. Women with ovarian cancer were treated with multimodal treatment to a greater extent than were the other diagnoses, which may indicate a more difficult treatment experience. In addition, ovarian cancer is associated with the poorest prognosis of all gynecologic cancers [9].

Health care organizational difficulties were described by approximately one quarter of the women in this study. These findings are in line with observations from the general cancer literature of limited service availability and accessibility concerning supportive care [34]. Other health care systems-based challenges have been reported, where women described difficulties with e.g., waiting times and scheduling. A desire for consistency and continuity in the health care organization was described in order to improve patients' experiences of care [40]. Results from a recent Australian survey of supportive care needs found health service and information needs to be most prevalent, representing eight of the top ten reported supportive care needs, with the highest ranked need 'being informed about your test results as soon as feasible' [27].

\section{Study limitations}

Although data analyzed were of a qualitative nature, participants were not interviewed but provided written answers to one specific question on needs and experiences after end of treatment, which precluded any further exploration of responses. On the other hand, it could be argued that the results truly represent what young women with gynecologic cancer consider important aspects of care following end-of-treatment, as the answers were not influenced by an interviewer. However, it must be noted that whether these results are representative of the experiences of women with gynecologic cancers of all ages, younger and older, cannot be established. Also, whether prior physical or psychological issues influenced these perceptions in any way is not known. Notably, our intention with the present study was not to provide generalizable conclusions, but rather to gain deeper understandings and generate hypotheses for future studies.
An important strength of the current study is the large number of participants included. This allowed a quantitative presentation of data in addition to the content analyses, which can be important in generating new hypotheses [25]. The different pattern of important aspects of care described between the different gynecologic cancers needs to be considered when interpreting the results. Results indicate that follow-up programs for young women suffering from gynecologic cancer need to consider the impact of the specific diagnosis on the disease trajectory. An important aspect for future research within psycho-oncology care is to evaluate how such programs best meet women's multidimensional needs. However, whether different treatment regimens, the psychological prerequisites of the types of cancer, or some other aspect of the disease influence needs warrant further exploration.

\section{Clinical implications}

Patterns of important aspects of care varied between the different diagnoses where women treated for ovarian cancer described unmet supportive care needs to a greater extent. At present, national guidelines are in place regarding follow-up care for women with gynecological cancer including being assigned a contact nurse through diagnosis, treatment and follow-up. However, there are regional variations and still, much focus remains on physical and medical issues during follow-up. Based on these results, we believe follow-up care after gynecological cancer must incorporate a broader view of support needs. Further studies exploring these patterns may be warranted, to develop more specific recommendations for psycho-oncology care and supportive care after gynecologic cancer.

\section{Conclusion}

In conclusion, results point to the importance of good quality care linked to the diagnosis and based on an understanding of a person's need, desire and expectation of support.

\section{Abbreviations \\ COREQ: Consolidated criteria for reporting qualitative research; ICD: International Statistical Classification of Diseases; N: numbers; PTSD: Post- traumatic Stress Disorder; SD: Standard Deviation; SPAR: Swedish personal address register.}

\section{Acknowledgments}

We gratefully acknowledge the contributions of the women who participated in this study, and the Swedish Quality Register of Gynecologic Cancer for providing assistance in identifying potential participants to the study.

\section{Authors' contributions}

Study conception and design: AW; Acquisition of data: KE, AW; Analysis and interpretation of data: EM, LL, KE, ISP, KS, AW; Drafting of manuscript: EM, LL, 
AW; Critical revision: EM, LL, KE, ISP, KS, AW; Authors have read and approved the final version of the manuscript.

\section{Funding}

Open Access funding provided by Uppsala University.

\section{Availability of data and materials}

Data sharing is not applicable to this article due to the ethically sensitive nature of the materials for which the authors do not have ethical permission to distribute. However, a de-identified dataset can potentially be made available by the corresponding author upon reasonable request, including an appropriate ethical approval.

\section{Ethics approval and consent to participate}

Ethical approval to conduct the study was granted by the Regional Ethical Review Board in Uppsala, Sweden (Reference number: 2016/221). Ethical approval comprised the procedure to collect informed consent, i.e., participants gave their written consent to participate by responding to the survey. Respondents were informed that by responding and returning the paper version of the survey or by answering the online version of the survey they consented to participate in the study. The date of response (paper/online) was recorded with the study code to document consent.

\section{Consent for publication}

Not applicable.

\section{Competing interests}

Over the past five years, ISP has served occasionally on advisory boards or acted as invited speaker at scientific meetings for MSD, Bayer Health Care, Gedeon Richter, Peptonics, Shire/Takeda, and Lundbeck A/S. All other authors declare that they have no conflicts of interest.

\section{Author details}

${ }^{1}$ Department of Health Care Sciences, Ersta Sköndal Bräcke University College, Stockholm, Sweden. ${ }^{2}$ Department of Women's and Children's Health, Uppsala University, Uppsala, Sweden.

Received: 20 May 2020 Accepted: 22 November 2020

Published online: 22 December 2020

\section{References}

1. Barr RD, Ferrari A, Ries L, Whelan J, Bleyer WA. Cancer in adolescents and young adults: a narrative review of the current status and a view of the future. JAMA Pediatr. 2016;170(5):495-501. https://doi.org/10.1001/jamap ediatrics.2015.4689.

2. Warner EL, Kent EE, Trevino KM, Parsons HM, Zebrack BJ, Kirchhoff AC. Social well-being among adolescents and young adults with cancer: a systematic review. Cancer. 2016;122(7):1029-37. https://doi.org/10.1002/ cncr.29866.

3. Bleyer A, Barr R. Cancer in young adults 20 to 39 years of age: overview. Semin Oncol. 2009;36(3):194-206. https://doi.org/10.1053/j.seminoncol 2009.03.003.

4. Mattsson E, Einhorn K, Ljungman L, Sundstrom-Poromaa I, Stalberg K, Wikman A. Women treated for gynecologic cancer during young adulthood - a mixed-methods study of perceived psychological distress and experiences of support from health care following end-of-treatment. Gynecol Oncol. 2018;149(3):464-9. https://doi.org/10.1016/j.ygyno .2018.03.055.

5. Geue K, Schmidt R, Sender A, Sauter S, Friedrich M. Sexuality and romantic relationships in young adult cancer survivors: satisfaction and supportive care needs. Psychooncology. 2015;24(11):1368-76. https://doi. org/10.1002/pon.3805.

6. Condorelli M, Lambertini M, Del Mastro L, Boccardo F, Demeestere I, Bober SL. Fertility, sexuality and cancer in young adult women. Curr Opin Oncol. 2019;31(4):259-67. https://doi.org/10.1097/CCO.0000000000 000540.

7. Bleyer AO, O'leary M, Barr, R.; Ries, LAG. Cancer epidemiology in older adolescents and young adults 15 to 29 years of age, including SEER Incidence and Survival: 1975-2000. Bethesda, MD 2006. NIH Pub No 06-5767.
8. The Swedish National Board of Health and Welfare. Statistics database. 2019 http://www.socialstyrelsen.se/statistik/statistikdatabas/cancer, (Accessed 12 Mar 2019).

9. American Cancer Society. Cancer facts \& figures 2016. Atlanta: American Cancer Society; 2016.

10. Lockwood-Rayermann S. Survivorship issues in ovarian cancer: a review. Oncol Nurs Forum. 2006;33(3):553-62. https://doi.org/10.1188/06. ONF.553-562.

11. Siegel RL, Miller KD, Jemal A. Cancer statistics, 2016. CA Cancer J Clin. 2016;66(1):7-30. https://doi.org/10.3322/caac.21332.

12. Ward KK, Shah NR, Saenz CC, McHale MT, Alvarez EA, Plaxe SC. Changing demographics of cervical cancer in the United States (1973-2008). Gynecol Oncol. 2012;126(3):330-3. https://doi.org/10.1016/j.ygyno .2012.05.035.

13. Rivera CM, Grossardt BR, Rhodes DJ, et al. Increased cardiovascular mortality after early bilateral oophorectomy. Menopause. 2009;16(1):15-23. https://doi.org/10.1097/gme.0b013e31818888f7.

14. Aerts L, Enzlin P, Verhaeghe J, Vergote I, Amant F. Psychologic, relational, and sexual functioning in women after surgical treatment of vulvar malignancy: a prospective controlled study. Int J Gynecol Cancer. 2014;24(2):372-80. https://doi.org/10.1097/IGC.0000000000000035.

15. Gonçalves V. Long-term quality of life in gynecological cancer survivors. Curr Opin Obstet Gynecol. 2010;22(1):30-5. https://doi.org/10.1097/ GCO.0b013e328332e626.

16. Hodgkinson K, Butow P, Fuchs A, Hunt GE, Stenlake A, Hobbs KM, Brand A, Wain G. Long-term survival from gynecologic cancer: psychosocial outcomes, supportive care needs and positive outcomes. Gynecol Oncol. 2007;104(2):381-9. https://doi.org/10.1016/j.ygyno.2006.08.036.

17. Manne S, Rini C, Rubin S, Rosenblum N, Bergman C, Edelson M, Hernandez E, Carlson J, Rocereto T. Long-term trajectories of psychological adaptation among women diagnosed with gynecological cancers. Psychosom Med. 2008;70(6):677-87. https://doi.org/10.1097/PSY.0b013e31817b935d.

18. Stafford L, Judd F, Gibson P, Komiti A, Mann GB, Quinn M. Anxiety and depression symptoms in the 2 years following diagnosis of breast or gynecologic cancer: prevalence, course and determinants of outcome. Support Care Cancer. 2015;23(8):2215-24. https://doi.org/10.1007/s0052 0-014-2571-y.

19. Urbaniec OA, Collins K, Denson LA, Whitford HS. Gynecological cancer survivors: assessment of psychological distress and unmet supportive care needs. J Psychosoc Oncol. 2011;29(5):534-51. https://doi. org/10.1080/07347332.2011.599829.

20. Hui D. Definition of supportive care: does the semantic matter? Curr Opin Oncol. 2014;26:372-9. https://doi.org/10.1097/CCO.0000000000000086.

21. Beesley VL, Alemayehu C, Webbb PM. A systematic literature review of the prevalence of and risk factors for supportive care needs among women with gynecologic cancer and their caregivers. Support Care Cancer. 2018;26:701-10. https://doi.org/10.1007/s00520-017-3971-6.

22. Phillips-Salimi CR, Andrykowski MA. Physical and mental health status of female adolescent/young adult survivors of breast and gynecological cancer: a national, population-based, case-control study. Support Care Cancer. 2013;21(6):1597-604. https://doi.org/10.1007/s00520-012-1701-7.

23. Rosenberg P, Kjølhede P, Staf C, Bjurberg M, Borgfeldt C, Dahm-Kähler P, Hellman K, Hjerpe E, Holmberg E, Stålberg K, Tholander B, Åvall Lundqvist E, Högberg T. Data quality in the Swedish quality register of gynecologic cancer - a Swedish Gynecologic Cancer Group (SweGCG) study. Acta Oncol. 2018;57(3):346-53. https://doi.org/10.1080/0284186X.2017.13660 48.

24. Weber R. Basic content analysis. London: Sage; 1990.

25. Sandelowski M. Real qualitative researchers do not count: the use of numbers in qualitative research. Res Nurs Health. 2001;24(3):230-40. https://doi.org/10.1002/nur.1025.

26. Tong A, Sainsbury P, Craig J. Consolidated criteria for reporting qualitative research (COREQ): a 32-item checklist for interviews and focus groups. Int J Qual Health Care. 2007;19(6):349-57 doi.org/10.1093/intqhc/mzm042.

27. Williams N, Griffin G, Farrell V, Rea A, Murray K, Hauck YL. The supportive care needs of women experiencing gynecologic cancer: a Western Australian cross-sectional study. BMC Cancer. 2018;18:912. https://doi. org/10.1186/s12885-018-4812-9.

28. Okediji PT, Salako O, Fatiregun OO. Pattern and predictors of unmet supportive care needs in cancer patients. Cureus. 2017;9:e1234. https://doi. org/10.7759/cureus.1234. 
29. McCallum M, Lefebvre M, Jolicoeur L, Maheu C, Lebel S. Sexual health and gynecological cancer: conceptualizing patient needs and overcoming barriers to seeking and accessing services. J Psychosom Obstet Gynaecol. 2012;33(3):135-42. https://doi.org/10.3109/0167482X.2012.709291.

30. Sekse RJT, Dunberger G, Olesen ML, Østerbye M, Seidbaek L. Lived experiences and quality of life after gynaecological cancer - an integrative review. J Clin Nurs. 2019;28(9-10):1393-421. https://doi.org/10.1111/ jocn.14721.

31. Rodríguez MAP, Suess A, Cerdá JCM, Carretero ME, Danet A. Opinions and expectations of women in the treatment of cervical and uterine cancer in Spain. Women Health. 2011;7(6):709-18. https://doi.org/10.2217/ whe.11.50.

32. Walton LM, Reeve J, Brown PM, Farquhar CM. Gynecologic cancer patients' needs and experiences of supportive health services in New Zealand. Psychooncology. 2010;19(2):201-8. https://doi.org/10.1002/ pon.1553.

33. Lydon A, Beaver K, Newbery C, Wray J. Routine follow-up after treatment for ovarian cancer in the United Kingdom (UK): patient and health professional views. Eur J Oncol Nurs. 2009;13(5):336-43. https://doi. org/10.1016/j.ejon.2009.04.007.

34. Dilworth S, Higgins I, Parker V, Kelly B, Turner J. Patient and health professional's perceived barriers to the delivery of psychosocial care to adults with cancer: a systematic review. Psychooncology. 2014;23(6):601-12. https://doi.org/10.1002/pon.3474.

35. Papadakos J, Bussière-Côté S, Abdelmutti N, Catton P, Friedman AJ, Massey C, Urowitz S, Ferguson SE. Informational needs of gynecologic cancer survivors. Gynecol Oncol. 2012;124(3):452-7. https://doi.org/10.1016/j. ygyno.2011.10.030.

36. Akkuzu G, Kurt G, Guvenc G, Kok G, Simsek S, Dogrusoy S, Ayhan A. Learning needs of gynecologic cancer survivors. J Cancer Educ. 2018;33(3):544-50. https://doi.org/10.1007/s13187-016-1118-y.

37. Beesley VL, Price MA, Webb PM, O'Rourke P, Marquart L, Butow PN. Changes in supportive care needs after first-line treatment for ovarian cancer: identifying care priorities and risk factors for future unmet needs. Psychooncology. 2012;22(7):1565-71. https://doi.org/10.1002/pon.3169.

38. Power J, Brown L, Ritvo P. A qualitative study examining psychosocial distress, coping, and social support across the stages and phases of epithelial ovarian cancer. Health Care Women Int. 2008;29(4):366-83. https:// doi.org/10.1080/07399330701876521.

39. Pistrang N, Jay Z, Gessler S, Barker C. Telephone peer support for women with gynecologic cancer: recipients' perspectives. Psychooncology. 2012;21(10):1082-90. https://doi.org/10.1002/pon.2005.

40. Long Roche K, Angarita AM, Cristello A, Lippitt M, Haider AH, Bowie JV, Fader AN, Tergas A. "Little big things": a qualitative study of ovarian cancer survivors and their experiences with the health care system. J Oncol Pract. 2016;12(12):e974-80. https://doi.org/10.1200/JOP.2015.00749.

\section{Publisher's Note}

Springer Nature remains neutral with regard to jurisdictional claims in published maps and institutional affiliations.
Ready to submit your research? Choose BMC and benefit from:

- fast, convenient online submission

- thorough peer review by experienced researchers in your field

- rapid publication on acceptance

- support for research data, including large and complex data types

- gold Open Access which fosters wider collaboration and increased citations

- maximum visibility for your research: over $100 \mathrm{M}$ website views per year

At BMC, research is always in progress.

Learn more biomedcentral.com/submissions 